\title{
Communication
}

\section{A Catalytically Active, Permanently Microporous MOF with Metalloporphyrin Struts}

Abraham M. Shultz, Omar K. Farha, Joseph T. Hupp, and SonBinh T. Nguyen

J. Am. Chem. Soc., 2009, 131 (12), 4204-4205• DOI: 10.1021/ja900203f • Publication Date (Web): 09 March 2009

Downloaded from http://pubs.acs.org on March 30, 2009

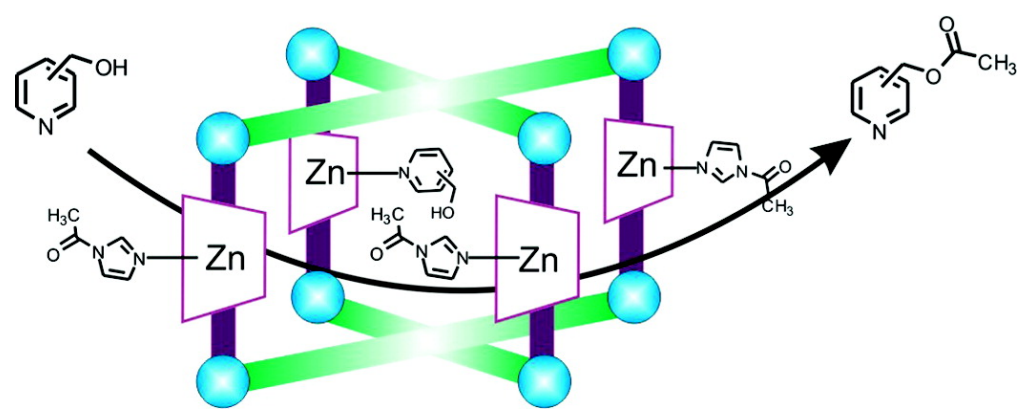

\section{More About This Article}

Additional resources and features associated with this article are available within the HTML version:

- Supporting Information

- Access to high resolution figures

- $\quad$ Links to articles and content related to this article

- Copyright permission to reproduce figures and/or text from this article

\section{View the Full Text HTML}




\title{
A Catalytically Active, Permanently Microporous MOF with Metalloporphyrin Struts
}

\author{
Abraham M. Shultz, Omar K. Farha, Joseph T. Hupp, ${ }^{*}$ and SonBinh T. Nguyen* \\ Department of Chemistry and Institute for Catalysis in Energy Processes, Northwestern University, \\ 2145 Sheridan Road, Evanston, Illinois 60208 \\ Received January 10, 2009; E-mail: j-hupp@ northwestern.edu; stn@northwestern.edu
}

Metal-organic frameworks (MOFs) have attracted significant attention because of their unique properties as permanently microporous materials. ${ }^{1}$ The ability to utilize a virtually unlimited range of organic struts, together with recent advances in purification ${ }^{2 \mathrm{a}}$ and postsynthesis manipulation, ${ }^{2 b}$ have facilitated the rational design of materials for many applications, such as gas storage, ${ }^{3}$ chemical separations, ${ }^{4}$ and catalysis, ${ }^{5}$ to name only a few. Analogues of homogeneous catalysts can be incorporated into MOF synthesis, allowing researchers to integrate the selectivity of well-defined, singlesite catalysts into the MOF micropores to perform shape-, size-, chemo-, or enantio-selective reactions. Moreover, the ability to separate and reuse a heterogeneous catalyst would be highly attractive in largescale reactions, where separation and waste disposal can be costly.

Metalloporphyrins should be ideal catalytic struts in MOFs, given their rigidity and well-studied catalytic behavior. ${ }^{6}$ It has proven surprisingly difficult, however, to create completely suitable porphyrinic frameworks, i.e., ones that simultaneously (a) exhibit permanent microporosity, (b) proffer sizable cavities (by precluding framework catenation), and (c) offer ready access to catalytic sites (e.g., by precluding 2D stacking or 3D self-coordination). ${ }^{7}$ Furthermore, of the several extant frameworks containing metalloporphyrin struts, only one has been shown to exhibit catalytic activity. ${ }^{8}$ Unfortunately, because of the constrained microporous channels in this structure, catalysis occurred only on the exterior of the framework. Herein, we report a mixed-ligand strategy for incorporating metalloporphyrins into frameworks featuring large pores that are suitable for catalysis. By using the tetratopic, "octa"-oxygen ligand 1,2,4,5-tetrakis(4-carboxyphenyl)benzene ${ }^{9}(\mathbf{1})$ in place of the more conventional dicarboxylic acids, we took advantage of the increased chelating ability of $\mathbf{1}$ to provide greater stability, and thus permanent microporosity, to the resulting MOF.

Combining $\mathrm{Zn}\left(\mathrm{NO}_{3}\right)_{2} \cdot 6 \mathrm{H}_{2} \mathrm{O}, \mathbf{1}$, and (5,15-dipyridyl-10,20bis(pentafluorophenyl))porphyrin (2) under solvothermal conditions (Figure 1) afforded purple block crystals of ZnPO-MOF, a zincbased, pillared paddlewheel MOF with the formula $\left[\mathrm{Zn}_{2}(\mathbf{1})(\mathrm{Zn}-\mathbf{2})\right]$. As expected, the free-base porphyrin 2 was metalated during the course of the solvothermal synthesis. The crystal structure of ZnPOMOF reveals large channels in three directions (Figure 2) that are occupied by a substantial amount of disordered solvent. Notably, ZnPO-MOF comprises a single independent framework, suggesting a high degree of porosity. This is in stark contrast with other pillared paddlewheel MOFs, where doubly or triply catenated structures are observed. $^{10}$

ZnPO-MOF is remarkably robust: the powder X-ray diffraction patterns of an as-synthesized sample and a sample that had been subjected to a cycle of evacuation and resolvation were nearly identical [Figure S3 in the Supporting Information (SI)]. In addition, thermogravimetric analysis (Figure S2 in the SI) demonstrated that no pore collapse occurs during the evacuation-resolvation procedure: the evacuated sample took up the same amount of solvent $(\sim 45 \mathrm{wt} \%)$ as the as-synthesized material. A reversible $\mathrm{CO}_{2}$ adsorption isotherm (Figure S4 in the SI) corroborated the permanent microporosity of ZnPO-MOF and indicated a gasaccessible surface area of $\sim 500 \mathrm{~m}^{2} / \mathrm{g}$. ${ }^{11}$

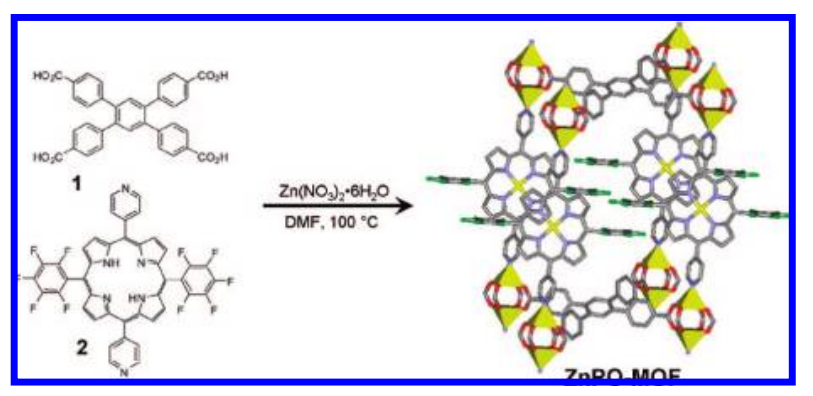

Figure 1. Synthesis of ZnPO-MOF. The stick representation of the unit cell is shown on the right-hand side (yellow polyhedra $=\mathrm{Zn}$, red $=\mathrm{O}$, green $=\mathrm{F}$, blue $=\mathrm{N}$, gray $=\mathrm{C}$ ). Solvent molecules, hydrogens, and disordered atoms have been omitted for clarity.

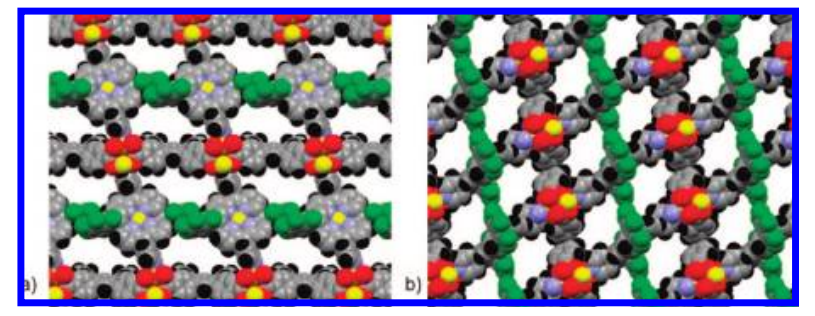

Figure 2. Space-filling models of the crystal structure of ZnPO-MOF (solvent omitted) showing channels down the $a$ and $b$ crystallographic axes (yellow $=\mathrm{Zn}$, red $=\mathrm{O}$, green $=\mathrm{F}$, blue $=\mathrm{N}$, gray $=\mathrm{C}$, black $=\mathrm{H})$ : (a) $15 \AA \times 9 \AA$ channels along the $a$ axis; (b) $11 \AA \times 9 \AA$ channels along the $b$ axis. The channels along the $c$ axis (not shown) are $8 \AA \times 9 \AA$.

While the preceding experiments are instructive, more helpful for understanding condensed-phase catalysis would be an assessment of the ability of dissolved reactants to reach potential catalytic sites. With this in mind, we exposed a sample of ZnPO-MOF to a solution of 3-pyridylcarbinol (3-PC), a substrate in acyl-transfer reactions catalyzed by $\mathrm{Zn}$-based supramolecules. ${ }^{12}$ The exposed material was then rinsed thoroughly with $\mathrm{CHCl}_{3}$ and dissolved in $\mathrm{D}_{2} \mathrm{SO}_{4} / \mathrm{D}_{2} \mathrm{O}$. The ${ }^{1} \mathrm{H}$ NMR spectra of the resulting solution revealed a 1:1 ratio of 3-PC to strut, indicating that all of the (porphyrin) $\mathrm{Zn}$ sites were accessible to the substrate.

To illustrate the catalytic capabilities of ZnPO-MOF, we employed the acyl-transfer reaction between $N$-acetylimidazole (NAI) and 3-PC (eq 1): ${ }^{12}$

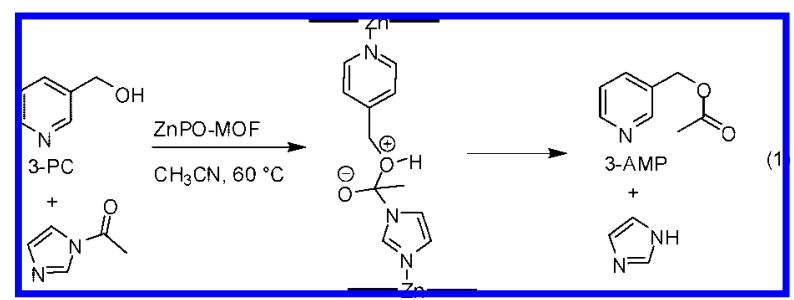


We observed a 2420 -fold rate enhancement relative to the uncatalyzed reaction (see the SI). A control experiment with a simpler MOF, $\mathrm{Zn}_{2}$ (p-terephthalate $)_{2}\left(4,4^{\prime}\right.$-bipyridine $)$, showed little catalysis. $^{13}$

Given the structure of ZnPO-MOF, one can envision at least three mechanisms by which reaction 1 might be accelerated. The first is simple Lewis acid (LA) activation: coordination of NAI to the unsaturated (porphyrin) $\mathrm{Zn}$ sites can stabilize a proximal negative charge (acyl oxygen) in the transition state (see the intermediate in eq 1). Second, coordination of the reactants to the (porphyrin) $\mathrm{Zn}$ sites can concentrate them within the MOF cavities and increase the rate of the reaction without changing the activation energy. Third, by binding complementary pairs of substrates within the nanoscale cavities, which have a $\mathrm{Zn}-\mathrm{Zn}$ separation distance of 11.6 $\AA$ (see Figure S1 in the SI), ZnPO-MOF might serve to orient and align the reactants in a fashion that is highly favorable for acyl transfer. (For closely related reactions catalyzed by discrete supramolecular assemblies in homogeneous solution, alignment optimization is known to be important. ${ }^{12}$ )

Depending on the relative distributions of the two substrates within the cavities (e.g., 1:99, 50:50, 99:1, etc.), we expect preconcentration to enhance the reaction rate by roughly 2 to 3.5 orders of magnitude. To gauge the importance of preferential substrate alignment, we extended the study to 2-PC and 4-PC (Figures S5 and S7 in the SI). The latter presents a different acyl orientation than 3-PC when bound to the $\mathrm{Zn}$ site, while the former is sterically incapable of binding. Figure 3 shows that there is surprisingly little sensitivity of the reaction rate to the substrate isomer structure, indicating that the third mechanism is of relatively little importance in the MOF-catalyzed acyl-transfer reaction, in sharp contrast to that observed for supramolecular catalysis. ${ }^{12}$

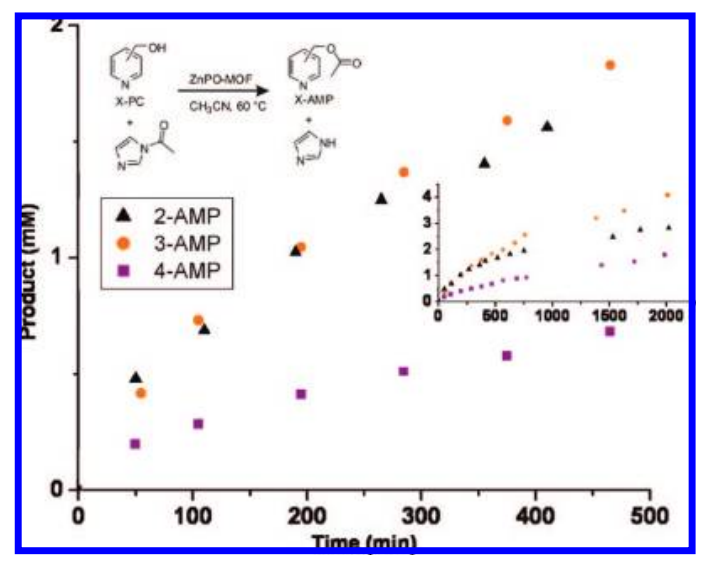

Figure 3. Plot of product concentrations vs time, showing the initial production of the various isomers of acetoxymethylpyridine (AMP) from $N$-acetylimidazole and pyridylcarbinols. The inset shows data at longer times.

To gauge the significance of LA activation, we tested (tetraphenylporphyrin) $\mathrm{Zn}$ (solution-phase monomer) as a catalyst. As detailed in the SI (see Figure S6), we observed only $\sim 22$-fold rate enhancement, suggesting that while LA activation is an important effect, it is less important than preconcentration. The product of the two effects (preconcentration and LA activation) experimentally yields an enhancement of only 2420 rather than 5900 (see the SI), suggesting that an inhibitory effect may also exist. Additional studies (see the SI) revealed that the imidazole product (a slightly stronger Lewis base than the NAI reactant) indeed behaves as a modest inhibitor, presumably by competing for catalytic $\mathrm{Zn}$ sites.
To summarize, we have demonstrated that by appropriate design of organic building blocks (dipyridyl pillars, robust tetratopic carboxylates), metalloporphyrins can be successfully incorporated into a MOF possessing the features needed for effective catalysis, i.e., large pores, permanent microporosity, and fully reactant-accessible active sites. Proof-of-concept catalysis of an acyl-transfer reaction revealed $\sim 2400$ fold rate enhancement, dominated by contributions from LA activation and reactant preconcentration. We hope to report shortly on variants of ZnPO-MOF featuring other metals as active sites and functioning catalytically by other mechanisms.

Acknowledgment. We acknowledge the U.S. Department of Energy (Grant DE-FG02-03ER15457), the Northwestern NSEC, AFOSR, NSF, and DTRA/ARO for financial support of this work.

Supporting Information Available: Synthesis and characterization data for $\mathbf{2}$ and ZnPO-MOF, including single-crystal X-ray diffraction data in CIF format, and a detailed description of reaction conditions and results for the acyl-transfer catalysis. This material is available free of charge via the Internet at http://pubs.acs.org.

\section{References}

(1) For recent reviews, see: Collins, D. J.; Zhou, H.-C. J. Mater. Chem. 2007, 17, 3154-3160. (b) Ferey, G. Chem. Soc. Rev. 2008, 37, 191-214.

(2) See, for example: (a) Farha, O. K.; Mulfort, K. L.; Thorsness, A. M.; Hupp, J. T. J. Am. Chem. Soc. 2008, 130, 8598-8599. (b) Gadzikwa, T.; Lu, G.; Stern, C. L.; Wilson, S. R.; Hupp, J. T.; Nguyen, S. T. Chem. Commun. 2008, 5493-5495.

(3) (a) Nouar, F.; Eubank, J. F.; Bosquet, T.; Wojitas, L.; Zaworotko, M. J.; Eddaoudi, M. J. Am. Chem. Soc. 2008, 130, 1833-1835. (b) Chen, B.; Ockwig, N. W.; Millard, A. R.; Contreras, D. S.; Yaghi, O. M. Angew. Chem. Int. Ed. 2005, 44, 4745-4749. (c) Dincă, M.; Dailly, A.; Liu, Y.; Brown, C. M.; Neumann, D. A.; Long, J. R. J. Am. Chem. Soc. 2006, 128 , 16876-16883. (d) Latroche, M.; Surble, S.; Serre, C.; Mellot-Draznieks, C.; Llewellyn, P. L.; Lee, H.; Chang, J.; Jhung, S. H.; Ferey, G. Angew. Chem., Int. Ed. 2006, 45, 8227-8231. (e) Mulfort, K. L.; Hupp, J. T. J. Am. Chem. Soc. 2007, 129, 9604-9605. (f) Farha, O. K.; Spokoyny, A. M.; Mulfort, K. L.; Hawthorne, M. F.; Mirkin, C. A.; Hupp, J. T. J. Am. Chem. Soc. 2007, 129, 12680-12681.

(4) (a) Lee, E. Y.; Jang, S. Y.; Suh, M. P. J. Am. Chem. Soc. 2005, 127, 63746381. (b) Dincă, M.; Long, J. R. J. Am. Chem. Soc. 2005, 127, 93769377. (c) Snurr, R. Q.; Hupp, J. T.; Nguyen, S. T. $A I C h E$ J. 2004, 50, 1090-1095. (d) Bae, Y. S.; Mulfort, K. L.; Frost, H.; Ryan, P.; Punnathanam, S.; Broadbelt, L. J.; Hupp, J. T.; Snurr, R. Q. Langmuir 2008, 24, 8592-8598. (e) Bae, Y. S.; Farha, O. K.; Spokoyny, A. M.; Mirkin, C. A.; Hupp, J. T.; Snurr, R. Q. Chem. Commun. 2008, 4135-4137. (f) Chen, B.; Liang, C.; Yang, J.; Contreras, D. S.; Clancy, Y. L.; Lobkovsky, E. B.; Yaghi, O. M.; Dai, S. Angew. Chem., Int. Ed. 2006, 45, 1390-1393.

(5) See, for example: (a) Cho, S.-H.; Ma, B.; Nguyen, S. T.; Hupp, J. T.; Albrecht-Schmitt, T. E. Chem. Commun. 2006, 2563-2565. (b) Hu, A.; Ngo, H. L.; Lin, W. J. Am. Chem. Soc. 2003, 125, 11490-11491. (c) Wu, C.-D.; Hu, A.; Zhang, L.; Lin, W. J. Am. Chem. Soc. 2005, 127, 89408941. (d) Alkordi, M. H.; Liu, Y.; Larsen, R. W.; Eubank, J. F.; Eddaoudi, M. J. Am. Chem. Soc. 2008, 130, 12639-12641. (e) Horike, S.; Dincă, M.; Tamaki, K.; Long, J. R. J. Am. Chem. Soc. 2008, 130, 5854-5855.

(6) Metalloporphyrins in Catalytic Oxidations; Sheldon, R. A., Ed.; Marcel Dekker: New York, 1994.

(7) See, for example: (a) Choi, E.-Y.; Barron, P. M.; Novotny, R. W.; Son, H.-T.; Hu, C.; Choe, W. Inorg. Chem. 2009, 48, 426-428. (b) Lin, K.-J. Angew. Chem., Int. Ed. 1999, 38, 2730-2732. (c) Pan, L.; Kelly, S.; Huang, X.; Li, J. Chem. Commun. 2002, 2334-2335. (d) Abrahams, B. F.; Hoskins, B. F.; Michail, D. M.; Robson, R. Nature 1994, 369, 727-729.

(8) Suslick, K. S.; Bhyrappa, P.; Chou, J.-H.; Kosal, M. E.; Nakagaki, S.; Smithenry, D. W.; Wilson, S. R. Acc. Chem. Res. 2005, 38, 263-291.

(9) Farha, O. K.; Mulfort, K. L.; Hupp, J. T. Inorg. Chem. 2008, 47, 1022310225.

(10) See, for example: Ma, B.-Q.; Mulfort, K. L.; Hupp, J. T. Inorg. Chem. 2005, 44, 4912-4914.

(11) An analysis of the crystal structure suggests that a substantially greater gas-accessible surface area $\left(\sim 3000 \mathrm{~m}^{2} / \mathrm{g}\right)$ should be observable. The reasons for the discrepancy are not clear. We note, however, that the more important property here is substrate accessibility of catalytic sites.

(12) (a) Mackay, L. G.; Wylie, R. S.; Sanders, J. K. M. J. Am. Chem. Soc. 1994, 116, 3141-3142. (b) Oliveri, C. G.; Gianneschi, N. C.; Nguyen, S. T.; Mirkin, C. A.; Stern, C. L.; Wawrzak, Z.; Pink, M. J. Am. Chem. Soc. 2006, 128, 16286-16296.

(13) However, when aggressive stirring was used (but not when controlled rocking was used), catalysis was observed after a lengthy induction period (see the SI). The catalysis can be ascribed to fragmentation of the MOF and exposure of zinc sites that otherwise play only a structural role.

JA900203F 